\title{
Different Mechanisms of Action of Regorafenib and Lenvatinib on Toll-Like Receptor-Signaling Pathways in Human Hepatoma Cell Lines
}

\author{
Reina Sasaki, Tatsuo Kanda *(D), Mariko Fujisawa, Naoki Matsumoto, Ryota Masuzaki, \\ Masahiro Ogawa, Shunichi Matsuoka, Kazumichi Kuroda and Mitsuhiko Moriyama \\ Division of Gastroenterology and Hepatology, Department of Medicine, Nihon University School of Medicine, \\ 30-1 Oyaguchi-kamicho, Itabashi-ku, Tokyo 173-8610, Japan; reina_sasaki_0925@yahoo.co.jp (R.S.); \\ mema17020@g.nihon-u.ac.jp (M.F.); matsumoto.naoki@nihon-u.ac.jp (N.M.); \\ masuzaki.ryota@nihon-u.ac.jp (R.M.); ogawa.masahiro@nihon-u.ac.jp (M.O.); \\ matsuoka.shunichi@nihon-u.ac.jp (S.M.); kuroda.kazumichi@nihon-u.ac.jp (K.K.); \\ moriyama.mitsuhiko@nihon-u.ac.jp (M.M.) \\ * Correspondence: kanda2t@yahoo.co.jp; Tel.: +81-3-3972-8111
}

Received: 7 April 2020; Accepted: 8 May 2020; Published: 9 May 2020

\begin{abstract}
Multiple kinase inhibitors are available for patients with advanced hepatocellular carcinoma (HCC). It is largely unknown whether regorafenib or lenvatinib modulates innate immunity including Toll-like receptor (TLR)-signaling pathways in HCC. We performed real-time RT-PCR to investigate 84 TLR-associated gene expression levels and compared these gene expression levels in each hepatoma cells treated with or without regorafenib or lenvatinib. In response to regorafenib, nine and 10 genes were upregulated in Huh7 and HepG2 cells, respectively, and only C-X-C motif chemokine ligand 10 was upregulated in both cell lines. A total of 14 and 12 genes were downregulated in Huh7 and HepG2 cells, respectively, and two genes (Fos proto-oncogene, AP-1 transcription factor subunit, and ubiquitin conjugating enzyme E2 N) were downregulated in both cell lines. In response to lenvatinib, four and 16 genes were upregulated in Huh7 and HepG2 cells, respectively, and two genes (interleukin 1 alpha and TLR4) were upregulated in both cells. Six and one genes were downregulated in Huh7 and HepG2, respectively, and no genes were downregulated in both cell lines. In summary, regorafenib and lenvatinib affect TLR signaling pathways in human hepatoma cell lines. Modulation of TLR signaling pathway may improve the treatment of HCC patients with refractory disease.
\end{abstract}

Keywords: c-JUN; c-FOS; CXCL10; gene expression; HCC; innate immunity; lenvatinib; regorafenib; sorafenib; toll-like receptor

\section{Introduction}

A systematic analysis for the Global Burden of Disease Study demonstrated that there were 953,000 incident cases of liver cancer and 819,000 related deaths in 2017 worldwide [1]. Hepatocellular carcinoma (HCC) is the most common type of liver cancer. It is not easy to detect the early stage of HCC, which is treated by hepatic resection, because even patents with advanced stage HCC show few symptoms [2,3]. Therefore, the development of treatments for HCC is an important issue.

HCC is a heterogeneous tumor with multiple epigenetic and genetic abnormalities $[4,5]$. Aberrant activation of several signaling cascades such as epidermal growth factor receptor (EGFR), Ras/extracellular signal-regulated kinase, phosphoinositol 3-kinase/mammalian target of rapamycin (mTOR), hepatocyte growth factor/mesenchymal-epithelial transition factor, Wnt, Hedgehog, and apoptotic signaling is often observed [6]. A multikinase inhibitor, sorafenib, has shown survival benefits in patients with advanced HCC $[7,8]$. Sorafenib has been approved as a first-line systemic 
chemotherapy for more than 10 years. After the use of sorafenib, the majority of advanced HCC patients are resistant to sorafenib [9]. We and others have reported that overexpression and phosphorylation of Jun proto-oncogene AP-1 transcription factor subunit (c-Jun) contributes to sorafenib resistance $[9,10]$. The biomarker companion study BIOSTORM showed that hepatocytic pERK and microvascular invasion predicted poor recurrence-free survival [11]. Thus, it is possible that several biomarkers may predict sorafenib benefit in HCC patients.

Regorafenib is one of the approved second-line kinase inhibitors shown to provide survival benefit in patients with HCC who have progressed during sorafenib treatment in Japan and other countries [12]. Lenvatinib was noninferior to sorafenib in terms of overall survival in untreated advanced HCC and is currently an approved kinase inhibitor for the treatment of advanced HCC [13]. Immune checkpoint inhibitors were first shown to be effective in melanoma and lung cancer. Recently immune checkpoint inhibitors have been applied in HCC treatment [14]. There have been several phase III clinical trials, including not only monotherapy with checkpoint inhibitors, programmed death-1 (PD-1) antibody nivolumab, PD-ligand 1 (PD-L1) antibody pembrolizumab, and cytotoxic T-lymphocyte-associated antigen 4 (CTLA-4) antibody tislelizumab, but also on combination therapy with nivolumab or pembrolizumab plus a molecular targeted agent (bevacizumab) or tislelizumab [14-18].

Although monoimmunotherapy is effective in only $20 \%$ of patients with solid cancer [19], Toll-like receptor (TLR) adjuvants may be useful for cancer immunotherapy [20]. TLR signaling pathways in HCC may modulate the treatment outcome of multiple kinase inhibitors with or without cancer immunotherapy. In the present study, we investigated whether regorafenib or lenvatinib modulates innate immunity including TLR-signaling pathways in human hepatoma cell lines. We observed that regorafenib upregulates C-X-C motif chemokine ligand 10 (CXCL10) and downregulates Fos proto-oncogene, AP-1 transcription factor subunit (c-FOS), and ubiquitin conjugating enzyme E2 N (UBE2N) and that lenvatinib upregulates interleukin 1 alpha (IL1A) and TLR4 in both Huh7 and HepG2 cells. Modulation of the TLR signaling pathway may improve the treatment of HCC patients with refractory disease. In the present study, we examined the mechanistic role of regorafenib and lenvatinib on cell proliferation and immunity of human hepatoma cell lines.

\section{Results}

\subsection{Effects of Regorafenib or Lenvatinib on Cell Viability in Human Hepatoma Cell Lines}

In the human body, the blood concentrations of sorafenib, regorafenib, and lenvatinib are $\sim 10 \mu \mathrm{M}$, $2 \mu \mathrm{M}$, and 0.07-0.1 $\mu \mathrm{M}$, respectively [9,21,22]. To examine the effects of these drugs on human hepatoma cell lines, Huh7 and HepG2 cells were treated with or without 1, 2, 5, 10, or $20 \mu \mathrm{M}$ sorafenib, regorafenib, or lenvatinib for $48 \mathrm{~h}$, and cell viability was measured by MTS assay. In Huh7 cells, more than $2 \mu \mathrm{M}$ sorafenib, regorafenib, and lenvatinib significantly altered cell viability, compared to that in the untreated control (Figure 1). In HepG2 cells, more than $5 \mu \mathrm{M}$ sorafenib or regorafenib, or $20 \mu \mathrm{M}$ lenvatinib significantly altered cell viability, compared to that in the untreated control (Figure 2).

We also examined the cell viabilities of Huh7 and HepG2 treated with or without 2 or $20 \mu \mathrm{M}$ regorafenib or lenvatinib for $48 \mathrm{~h}$, using trypan blue dye exclusion assay. In Huh7 cells treated with 0,2 , or $20 \mu \mathrm{M}$ regorafenib, cell viabilities (\%) were $98.1 \pm 1.6,97.1 \pm 0.8$ (no statistical difference, compared with untreated control, $n=3)$, and $22.6 \pm 7.4(p<0.05$, compared with untreated control, $n=3)$, respectively. In Huh7 cells treated with 0, 2, or $20 \mu \mathrm{M}$ lenvatinib, cell viabilities (\%) were $98.1 \pm 1.6$, $94.0 \pm 3.6$ (no statistical difference, compared with untreated control, $n=3$ ), and $3.3 \pm 0.5(p<0.05$, compared with untreated control, $n=3$ ), respectively (Figure 1D-H). In HepG2 cells treated with 0, 2 , or $20 \mu \mathrm{M}$ regorafenib, cell viabilities (\%) were $98.6 \pm 0.3,99.0 \pm 1.7$ (no statistical difference, compared with untreated control, $n=3)$, and $16.7 \pm 28.9(p<0.05$, compared with untreated control, $n=3)$, respectively. In HepG2 cells treated with 0,2 , or $20 \mu \mathrm{M}$ lenvatinib, cell viabilities (\%) were $98.6 \pm 0.3$, $97.9 \pm 0.7$ (no statistical difference, compared with untreated control, $n=3)$, and $29.6 \pm 8.2(p<0.05$, compared with untreated control, $n=3$ ), respectively (Figure 2D-H). Because of no effects of $2 \mu \mathrm{M}$ 
regorafenib or $2 \mu \mathrm{M}$ lenvatinib on cell viabilities were observed, we used these concentrations of both drugs for the PCR array experiment.

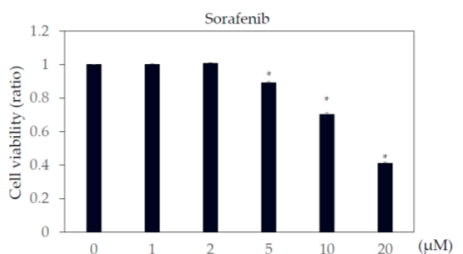

(A)

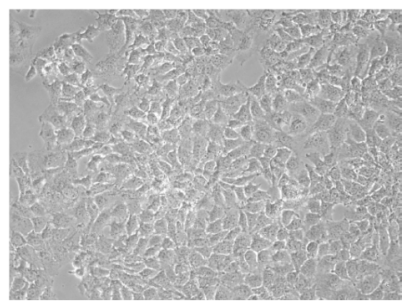

(D)

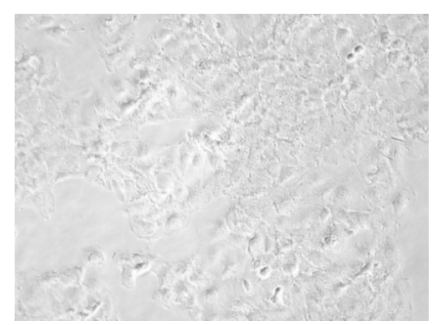

(G)

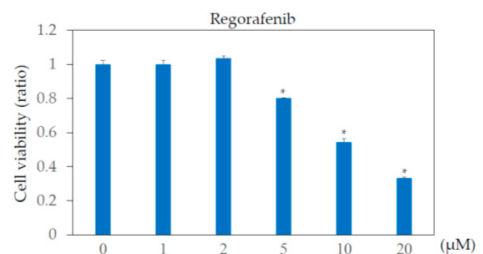

(B)

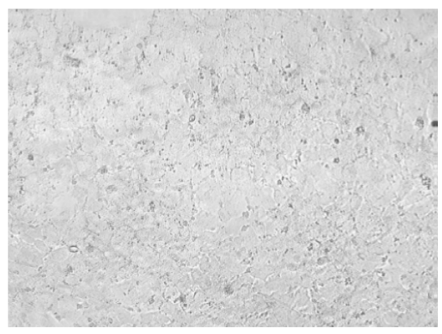

(E)

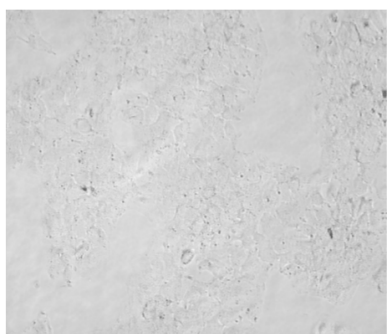

$(\mathrm{H})$

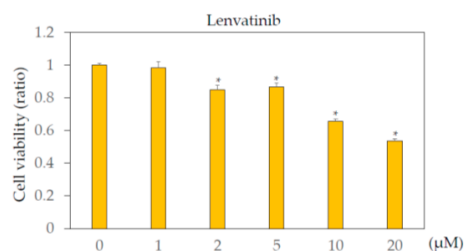

(C)

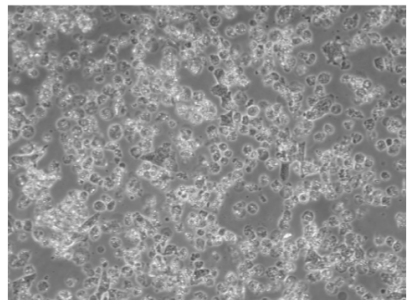

(F)

Figure 1. Effects of multiple kinase inhibitors on the Huh7 cell viability cells $(n=3)$, (A) sorafenib; (B) regorafenib; (C) lenvatinib. Huh7 cells were treated with sorafenib, regorafenib or lenvatinib at $0,1,2,5,10$, or $20 \mu \mathrm{M}$ for $48 \mathrm{~h}$. Cell viability was measured by MTS assay. ${ }^{*} p<0.05$, compared to Huh7 treated without multiple kinase inhibitors. Pictures taken by phase contrast microscopy $(\times 20)$ : (D) Huh7 control; (E) Huh7 cells treated with $2 \mu \mathrm{M}$ regorafenib; (F) $20 \mu \mathrm{M}$ regorafenib; (G) $2 \mu \mathrm{M}$ lenvatinib; (H) $20 \mu \mathrm{M}$ lenvatinib.

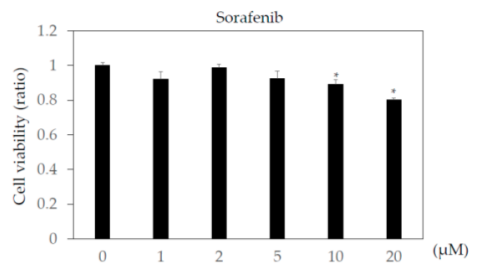

(A)

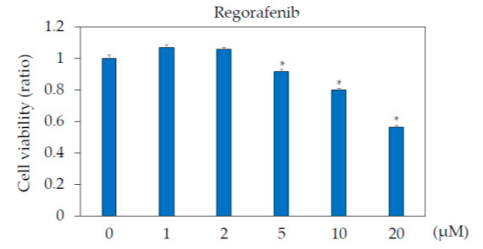

(B)

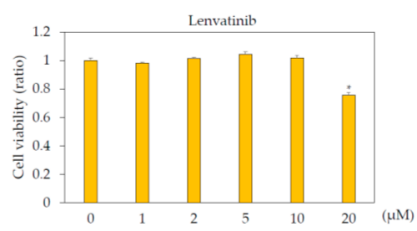

(C)

Figure 2. Cont. 


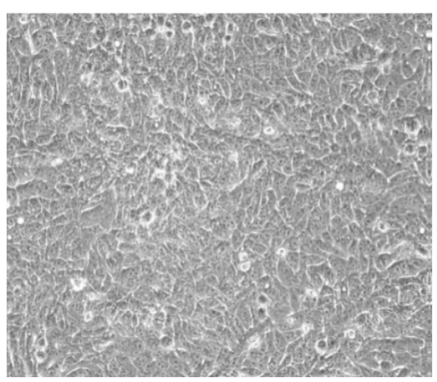

(D)

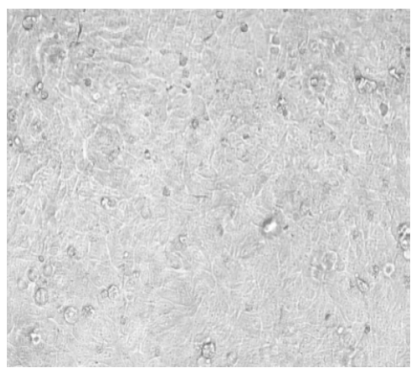

(G)

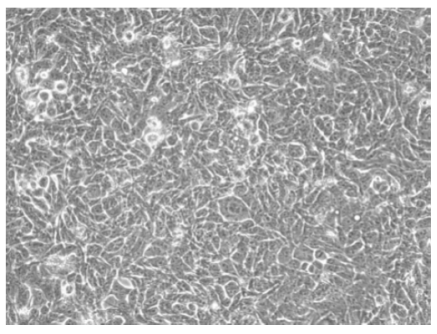

(E)

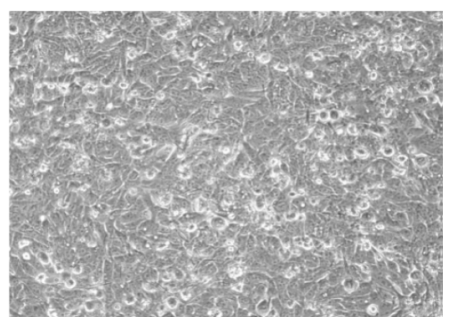

$(\mathrm{H})$

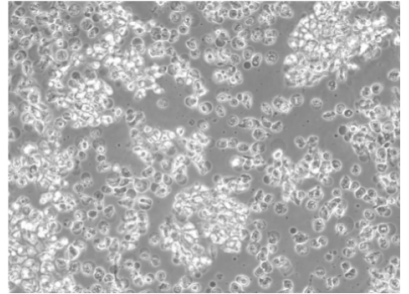

(F)

Figure 2. Effects of multiple kinase inhibitors on the HepG2 cell viability cells $(n=3)$, (A) sorafenib; (B) regorafenib; (C) lenvatinib. HepG2 cells were treated with sorafenib, regorafenib, or lenvatinib at $0,1,2,5,10$, or $20 \mu \mathrm{M}$ for $48 \mathrm{~h}$. (A) sorafenib; (B) regorafenib; (C) lenvatinib. Cell viability was measured by MTS assay. ${ }^{*} p<0.05$, compared to HepG2 treated without multiple kinase inhibitors. Pictures taken by phase contrast microscopy $(\times 20)$ : (D) HepG2 control; (E) HepG2 cells treated with $2 \mu \mathrm{M}$ regorafenib; (F) $20 \mu \mathrm{M}$ regorafenib; (G) $2 \mu \mathrm{M}$ lenvatinib; (H) $20 \mu \mathrm{M}$ lenvatinib.

\subsection{Effects of Regorafenib on the Toll-Like Receptor (TLR) Signaling Pathway in Human Hepatoma Cell Lines}

It is possible that multiple kinase inhibitors, such as regorafenib and lenvatinib, have effects on innate immunity, including the TLR pathway. TLR ligands have been used as adjuvants for traditional vaccines, and they may also play a role in enhancing the efficacy of tumor immunotherapy $[19,20,23]$. In this study, the effects of multiple kinase inhibitors on innate immunity, including the TLR signaling pathway, were examined in human hepatoma cell lines.

We examined TLR-related gene expression profiles using a real-time PCR-based focused array to investigate the effects of regorafenib on the TLR signaling pathway in Huh7 cells and HepG2 cells. A comparison of TLR-related genes between regorafenib-treated and untreated control Huh7 or HepG2 cells after $24 \mathrm{~h}$ of treatment with $2 \mu \mathrm{M}$ regorafenib is shown in Figure 3. Out of 84 TLR-related genes examined, nine $(10.7 \%)$ were significantly upregulated in Huh7 cells treated with regorafenib compared to control cells $(n=3, p<0.05)$, while $10(11.9 \%)$ were significantly upregulated in HepG2 cells treated with regorafenib compared to control cells $(n=3, p<0.05)$. The response to regorafenib revealed eight genes unique to Huh7 cells and nine unique to HepG2 cells; only CXCL10 was upregulated in both human hepatoma cell lines. Two genes (CXCL10 and TLR3) were upregulated two-fold or more in Huh7 cells $(n=3, p<0.05)$ and two genes (CXCL10 and BTK) were upregulated two-fold or more in HepG2 cells $(n=3, p<0.05)$. The significantly upregulated genes are summarized in Figure 3A. 


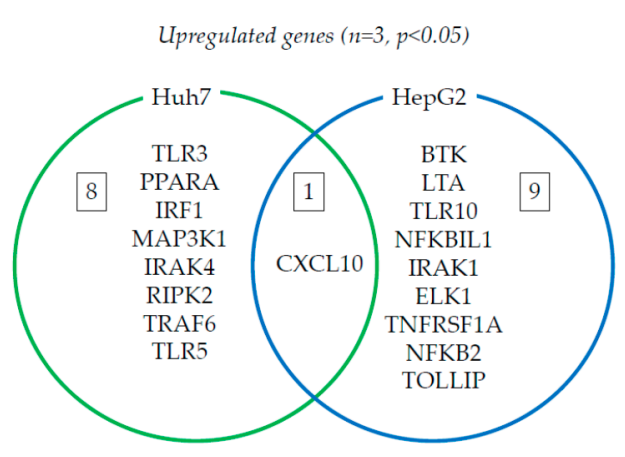

(A)

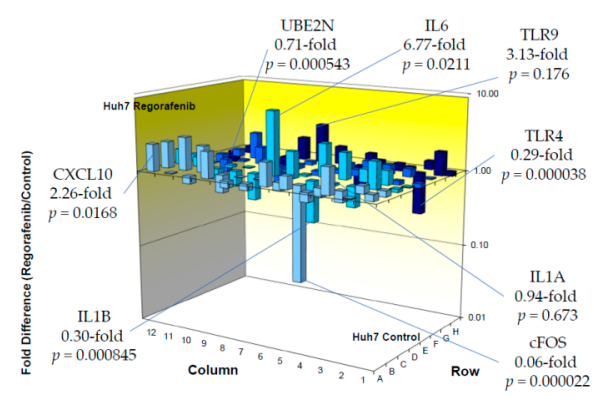

(C)

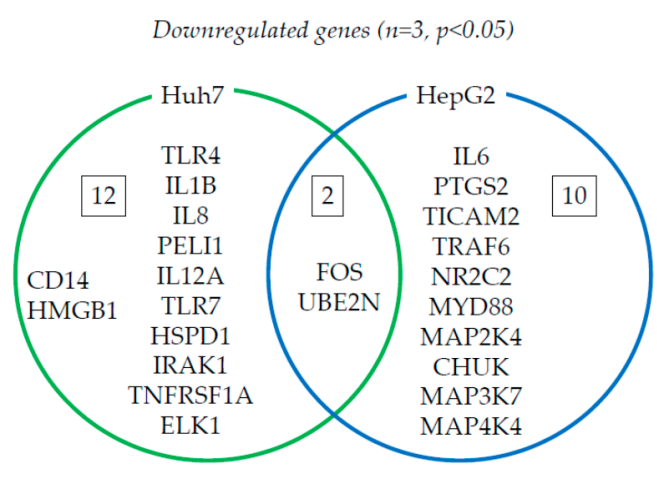

(B)

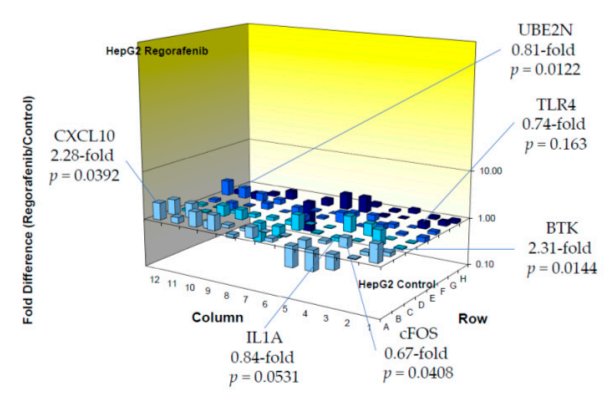

(D)

Figure 3. Effects of regorafenib treatment on Toll-like receptor (TLR)-related gene expression in human hepatoma Huh7 and HepG2 cells: (A) Upregulated genes $(p<0.05)$; (B) Downregulated genes $(p<0.05)$; (C) Changes of TLR-related gene expression in Huh7 cells treated with or without regorafenib; (D) Changes of TLR-related gene expression in HepG2 cells treated with or without regorafenib. Cells were treated with or without $2 \mu \mathrm{M}$ regorafenib for $24 \mathrm{~h}$ and cellular RNA was extracted. Eighty-four TLR-related genes were evaluated by real-time PCR-based array $(n=3)$. $p$-values, compared to those of untreated cells.

On the other hand, out of 84 genes, 14 (16.7\%) were significantly downregulated in Huh7 cells treated with regorafenib compared to control cells $(n=3, p<0.05)$, while $12(14.3 \%)$ were significantly downregulated in HepG2 cells treated with regorafenib compared to control cells $(n=3, p<0.05)$. Among them, 12 genes were unique to Huh7, 10 were unique to HepG2 and two genes (FOS and UBE2N) were downregulated in both cell lines. Three genes (FOS, TLR4 and IL1B) were downregulated two-fold or more in Huh7 cells $(n=3, p<0.05)$ and only FOS was downregulated five-fold or more in Huh7 cells $(n=3, p<0.05)$. No genes were downregulated two-fold or more in HepG2 cells $(n=3, p<0.05)$. The significantly downregulated genes are summarized in Figure 3B. Figure 3C,D demonstrate three-dimensional profile of TLR-related gene expression by the treatment of regorafenib in Huh7 and HepG2, respectively.

\subsection{Effects of Lenvatinib on the Toll-Like Receptor (TLR) Signaling Pathway in Human Hepatoma Cell Lines}

Next, we examined TLR-related gene expression profiles using a real-time PCR-based focused array to investigate the effects of lenvatinib on the TLR signaling pathway in Huh7 cells and HepG2 cells. A comparison of TLR-related genes between lenvatinib-treated and untreated control Huh7 or HepG2 cells after $24 \mathrm{~h}$ of treatment with $2 \mu \mathrm{M}$ lenvatinib is shown in Figure 4. Out of 84 TLR-related genes examined, four genes $(4.8 \%)$ were significantly upregulated in Huh7 cells treated with lenvatinib compared to control cells $(n=3, p<0.05)$, while $16(19.0 \%)$ were significantly upregulated in HepG2 
cells treated with lenvatinib compared to control cells $(n=3, p<0.05)$. The response to lenvatinib revealed two genes unique to Huh7 cells, 14 unique to HepG2 cells, and two genes (IL1A and TLR4) upregulated in both human hepatoma cell lines. Only BTK was upregulated two-fold or more in Huh7 cells $(n=3, p<0.05)$. Seven genes (CXCL10, CSF2, IL6, TLR4, LY96, IRAK2 and IL1B) were upregulated two-fold or more in HepG2 cells ( $n=3, p<0.05$ ), and only CXCL10 was upregulated five-fold or more in HepG2 cells $(n=3, p<0.05)$. The significantly upregulated genes are summarized in Figure 4A.

On the other hand, out of 84 genes, six (7.1\%) were significantly downregulated in Huh7 cells treated with lenvatinib compared to control cells $(n=3, p<0.05)$, while only PTGS2 $(1.2 \%)$ was significantly downregulated in HepG2 cells treated with lenvatinib compared to control cells $(n=3$, $p<0.05)$. Among them, six genes were unique to Huh7, one was unique to HepG2, and no genes were downregulated in either cell line. No genes were downregulated two-fold or more in Huh7 $(n=3$, $p<0.05)$ or HepG2 $(n=3, p<0.05)$ cells. The significantly downregulated cells are summarized in Figure 4B. Figure 4C,D demonstrate three-dimensional profile of TLR-related gene expression by the treatment of lenvatinib in Huh7 and HepG2, respectively.

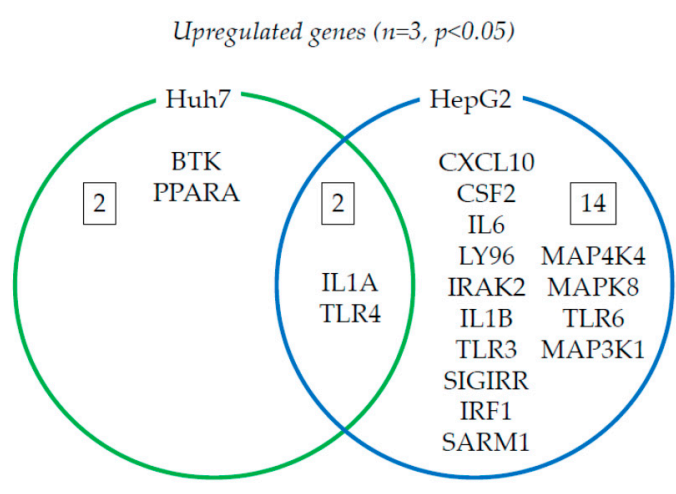

(A)

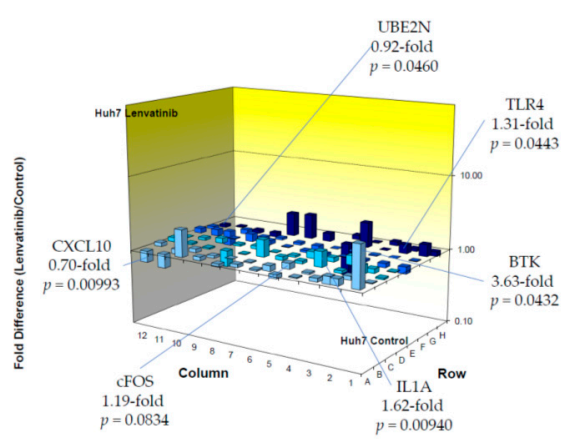

(C)

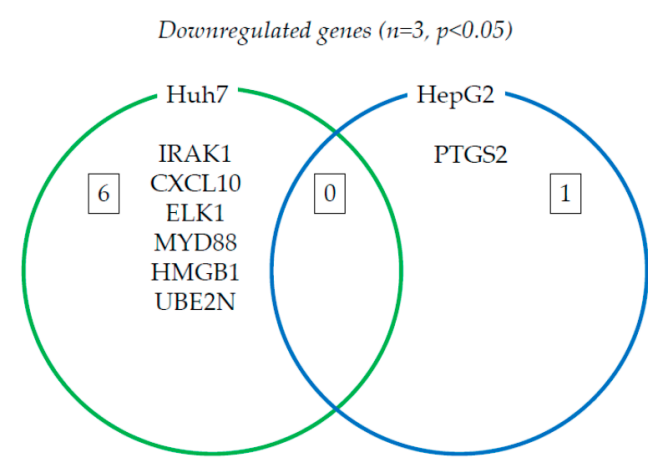

(B)

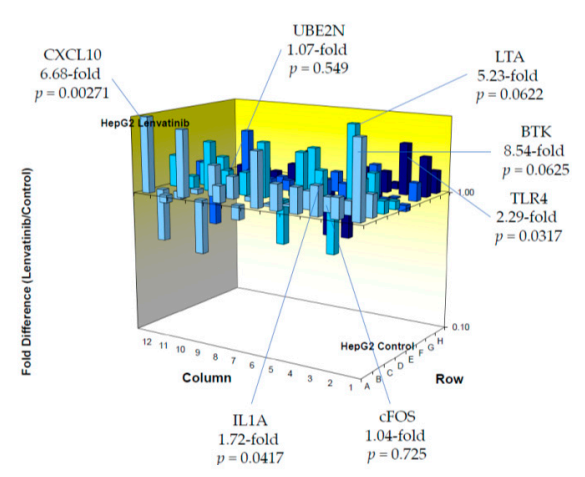

(D)

Figure 4. Effects of lenvatinib treatment on Toll-like receptor (TLR)-related gene expression in human hepatoma Huh7 and HepG2 cells: (A) Upregulated genes $(p<0.05)$; (B) Downregulated genes $(p<0.05)$. (C) Changes of TLR-related gene expression in Huh7 cells treated with or without lenvatinib; (D) Changes of TLR-related gene expression in HepG2 cells treated with or without lenvatinib. Cells were treated with or without $2 \mu \mathrm{M}$ lenvatinib for $24 \mathrm{~h}$ and cellular RNA was extracted. Eighty-four TLR-related genes were evaluated by real-time PCR-based array $(n=3)$. $p$-values, compared to those of untreated cells. 


\subsection{Ingenuity Pathway Analysis (IPA) with Five Genes (CXCL10, FOS, UBE2N, IL1A, and TLR4)}

We found five genes (CXCL10, FOS, UBE2N, IL1A, and TLR4) that were significantly changed by regorafenib or lenvatinib in both Huh7 and HepG2 cells. Furthermore, IPA was performed to show that both cell lines and TLR related pathways were prominently influenced by regorafenib and lenvatinib. IPA was applied with a particular focus on the details of the underlying algorithms, and the application to a number of real-world use cases [24]. We performed IPA with these five genes to predict downstream effects and identify new targets or candidate biomarkers (Figure 5). IPA revealed that these five genes that are commonly regulated by both regorafenib and lenvatinib; moreover, they are closely associated with cell proliferation signaling pathways, supporting the results that these two drugs have inhibitory effects on cell proliferation (Figures 1 and 2).

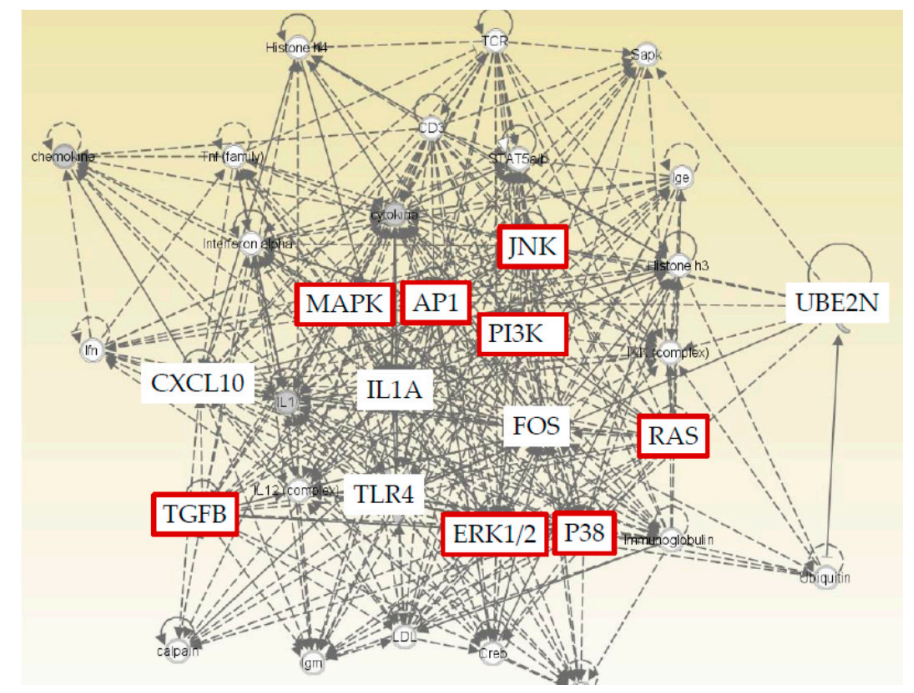

Figure 5. Ingenuity Pathway Analysis (IPA) of five genes (CXCL10, FOS, UBE2N, IL1A, and TLR4) that are commonly regulated by both regorafenib and lenvatinib showed a close association with cell proliferation signaling pathways (red color).

\section{Discussion}

Sorafenib was the first systemic therapy approved for patients with advanced-stage HCC, after the SHARP trial revealed an improvement in median overall survival from 7.9 to 10.7 months [7]. Currently, regorafenib, as a second-line treatment, and lenvatinib have been approved and demonstrated to improve the clinical outcomes of patients with advanced HCC. However, the median overall survival remains $\sim 1$ year with these new drugs being used in most patients with advanced HCC [12,13]. Thus, novel therapeutic strategies are still needed to extend the lives of patients with advanced HCC. In the present study, we investigated the molecular mechanisms of lenvatinib and regorafenib in the innate immunity of human hepatoma cell lines to define the effect of these anticancer agents and to support the investigation of novel therapeutic strategies.

We observed significant upregulation of CXCL10 expression in both Huh7 and HepG2 cells treated with regorafenib compared to untreated cells (Figure 3A). CXCL10 is associated with interferon regulatory factor (IRF) signaling and enhances the migration, invasion, and metastasis of HCC cells by activating matrix metallopeptidase-2 (MMP-2) expression [25]. c-FOS and UBE2N expression were significantly downregulated in both cells treated with regorafenib compared to untreated cells (Figure 3B). Interestingly, regorafenib downregulated c-FOS expression, resulting in the suppression of AP-1 activation, which is occasionally seen in sorafenib-resistant HCC $[9,10]$. Therefore, regorafenib may be effective for treating sorafenib-resistant HCC. UBE2N is related to NF- $\mathrm{kB}$ signaling and is required for the development of breast cancer metastasis [26]. 
There was significant upregulation of IL1A and TLR4 expression in both Huh7 and HepG2 cells treated with lenvatinib compared to untreated cells (Figure 4A). IL1A, which is related to cytokine signaling downstream of TLR, has emerged as an apical driver of inflammation and cancer in the colon [27] and is also associated with distant metastases and poor survival rates in head and neck squamous cell carcinoma and gastric carcinoma [28,29]. TLR4, which has an important role in regulating innate and adaptive immune responses, is expressed in HCC cells and promotes HCC cell proliferation $[30,31]$.

Lipopolysaccharide (LPS) was one of the TLR4 ligands. LPS induced apoptosis of HepG2 was inhibited by decreasing expression of TLR4, associated with hepatitis C virus infection [30]. We observed the downregulation of TLR4 mRNA in HepG2 cells treated with $2 \mu \mathrm{M}$ regorafenib and the upregulation of TLR4 mRNA in HepG2 cells treated with $2 \mu \mathrm{M}$ lenvatinib (Figure 4C,D). Although we also examined whether $100 \mathrm{ng} / \mathrm{mL}$ LPS could enhance the effects of $2 \mu \mathrm{M}$ regorafenib or $2 \mu \mathrm{M}$ lenvatinib on cell death, we did not observe any differences of cell death between two drugs (data not shown).

Our findings for IL1A and TLR4 mRNA upregulation induced by lenvatinib is important (Figure 4A). It could be valid for the immune cells although our experimental study was performed in two human hepatoma cell lines. Since interleukin-1 receptor and TLR4 signaling triggers MYD88 innate immune signal transduction adaptor (MyD88) activation cascade in monocytes, the effect of levantinib could be not only on hepatoma cells, but also on monocytes. Our results could support the basis of concept that lenvatinib, a first line drug for HCC, synergizes with immunotherapy to inhibit the immunosuppressive tumor environment, via the inhibition of the monocytes to tumor-associated macrophages transition or the inhibition of vascular endothelial growth factors as the main mechanism $[32,33]$. Further study is needed.

A human phase II clinical trial using an anti-CXCL10 monoclonal antibody (MDX-1100) for rheumatoid arthritis patients who had an inadequate response to methotrexate treatment showed that blocking CXCL10 significantly increased the response rate compared to that in the placebo group, suggesting a possible therapeutic use in humans [34]. MABp1 is a human antibody targeting IL1A and is undergoing clinical trials for moderate to severe hidradenitis suppurativa patients not eligible for adalimumab [35]. TLR4 inhibitors (eritoran and resatorvid) and TLR4 agonists (GSK1795091, OM174) are also under clinical trials [36-39]. New multiple kinase inhibitors, such as ramucirumab and cabozantinib, and monoimmunotherapy are available or will be available soon. Drugs against these molecules may enhance the effects of multikinase inhibitors on HCC.

\section{Materials and Methods}

\subsection{Cell Culture and Regents}

Human hepatoma cell lines HepG2 and Huh7 were used as previously described [9,40]. Cells were maintained in Roswell Park Memorial Institute medium (RPMI1640) (Sigma-Aldrich, St. Louis, MO, USA) supplemented with $10 \%$ fetal calf serum (FCS) and $200 \mathrm{U} / \mathrm{mL}$ penicillin and $200 \mu \mathrm{g} / \mathrm{mL}$ streptomycin at $37^{\circ} \mathrm{C}$ in a $5 \% \mathrm{CO}_{2}$ atmosphere. Sorafenib, regorafenib, and lenvatinib were purchased from AdooQ Bioscience (Irvine, CA, USA), Cayman Chemical (Ann Arbor, MI, USA), and ChemScene LLC (Monmouth Junction, NJ, USA), respectively.

\subsection{MTS Assay and Trypan Blue Dye Exclusion Assay}

Cells were treated with sorafenib, regorafenib, or lenvatinib at $0,1,2,5,10$, or $20 \mu \mathrm{M}$ for $48 \mathrm{~h}$. To determine cell viability, the CellTiter 96 AQueous One Solution Cell Proliferation Assay (Promega, Madison, WI, USA) was used [9]. Living cells converted 5-(3-carboxymethoxyphenyl)-2(4,5-dimenthylthiazoly)-3-(4-sulfophenyl) tetrazolium, inner salt (the MTS tetrazolium compound) to formazan. To perform the MTS assay, MTS solution was added to each well. Four hours later, the absorbance of each cells at $490 \mathrm{~nm}$ was measured with the iMark Microplate Absorbance Reader (Bio-Rad, Tokyo, Japan). 
Cells were treated with regorafenib or lenvatinib at 0,2 , or $20 \mu \mathrm{M}$ for $48 \mathrm{~h}$. Cell pictures were also taken by phase contrast microscopy (BIOREVIO BZ-9000, Keyence, Osaka, Japan). Cell suspension were also stained with $0.4 \%$ trypan blue dye (Invitrogen, Carlsbad, CA, USA), and both live and dead cells were counted under phase contrast microscopy [41].

\subsection{RNA Extraction, cDNA Synthesis and Human TLR Signaling Targets PCR Array}

Twenty-four hours before treatment, approximately $0.5 \times 10^{6}$ cells were plated into each well of six-well plates. Cells were treated with or without $2 \mu \mathrm{M}$ regorafenib or $2 \mu \mathrm{M}$ lenvatinib for $24 \mathrm{~h}$ and cellular RNA was extracted using the RNeasy Mini Kit (Qiagen, Hilden, Germany). RNA was quantified by using a NanoDrop ND-1000 spectrophotometer (Thermo Fisher, Tokyo, Japan), and $0.5 \mu \mathrm{g}$ RNA was subjected to each reaction. cDNA was synthesized with an $\mathrm{RT}^{2}$ First Strand cDNA Kit (Qiagen) for $15 \mathrm{~min}$ at $42{ }^{\circ} \mathrm{C}$, for $5 \mathrm{~min}$ at $95{ }^{\circ} \mathrm{C}$, and for min at $72{ }^{\circ} \mathrm{C}$. A human TLR signaling pathway PCR array was purchased from Qiagen. The 84 genes associated with the TLR signaling pathway assessed by real-time RT-PCR are listed in Supplementary Table S1 [42]. A real-time PCR array based on the SYBR Green method was performed on a 7500 Fast real-time PCR system (Applied Biosystems, Foster, CA, USA). The cycling program was as follows: $95^{\circ} \mathrm{C}$ for $10 \mathrm{~min}$ for one cycle, then 40 cycles of $95^{\circ} \mathrm{C}$ for $15 \mathrm{~s}$ and $60^{\circ} \mathrm{C}$ for $1 \mathrm{~min}$. The relative gene expression levels were normalized to five housekeeping gene levels by using the $2-\Delta \Delta C T$ formula $(\Delta \Delta C T=\Delta C T$ sample $-\triangle C T$ untreated control). Data were analyzed by the RT2 Profiler PCR Array Data Analysis software (http://pcrdataanalysis.sabiosciences.com/pcr/arrayanalysis.php). The analysis of potential target genes was carried out using IPA (Qiagen). Gene expression changes were considered statistically significant at $p<0.05$.

\subsection{Statistical Analysis}

The results are presented as the means \pm standard deviations of triplicate determinations from one experiment, representative of three independent experiments. Data were analyzed by Student's $t$ test with a two-tailed distribution. A $p$-value of $<0.05$ was considered statistically significant.

\section{Conclusions}

Regorafenib and lenvatinib have effects on TLR signaling pathways in human hepatoma cell lines (Supplementary Table S1). Regorafenib and lenvatinib also have different actions in innate immunity. However, there exist some limitations in this study. First, as we used only two hepatoma cell lines; we should confirm the results in an in vivo study. Second, although we observed the change of gene expression levels, we did not see the protein expression levels or downstream signaling mechanism. Third, although hepatocyte is one of the immune cells [43], we did not examine the interaction between hepatocytes and other immune cells $[32,33,44-46]$.

Our study is limited, but it is the beginning of our project. These limitations could be addressed in future research. Regorafenib downregulates c-FOS expression, resulting in the suppression of AP-1 activation, which is occasionally seen in sorafenib-resistant HCC $[9,10]$. Innate immune response pathways play important roles in exerting the effects of molecularly targeted drugs against HCC. Modulation of the TLR signaling pathway may improve the treatment of HCC patients with refractory disease.

Supplementary Materials: Supplementary materials can be found at http://www.mdpi.com/1422-0067/21/9/3349/s1. Table S1. The 84 genes associated with Toll-like receptor signaling pathway assessed by real-time RT-PCR, and gene expression of regorafenib (vs. lenvatinib) in the present study.

Author Contributions: Conceptualization, R.S. and T.K.; methodology, R.S. and T.K.; software, M.F. and K.K.; validation, T.K.; formal analysis, R.S. and T.K.; investigation, T.K.; writing-original draft preparation, R.S. and T.K.; writing-review and editing, R.S. and T.K.; supervision, N.M., R.M., M.O., S.M., and M.M.; project administration, R.S. and T.K.; funding acquisition, T.K. All authors have read and agreed to the published version of the manuscript. 
Funding: This work was supported by JSPS KAKENHI Grant Number JP17K09404 (to T.K.).

Conflicts of Interest: T.K. received research grants from Eisai Co., LTD. The funders had no role in the design of the study; in the collection, analyses, or interpretation of data; in the writing of the manuscript; or in the decision to publish the results.

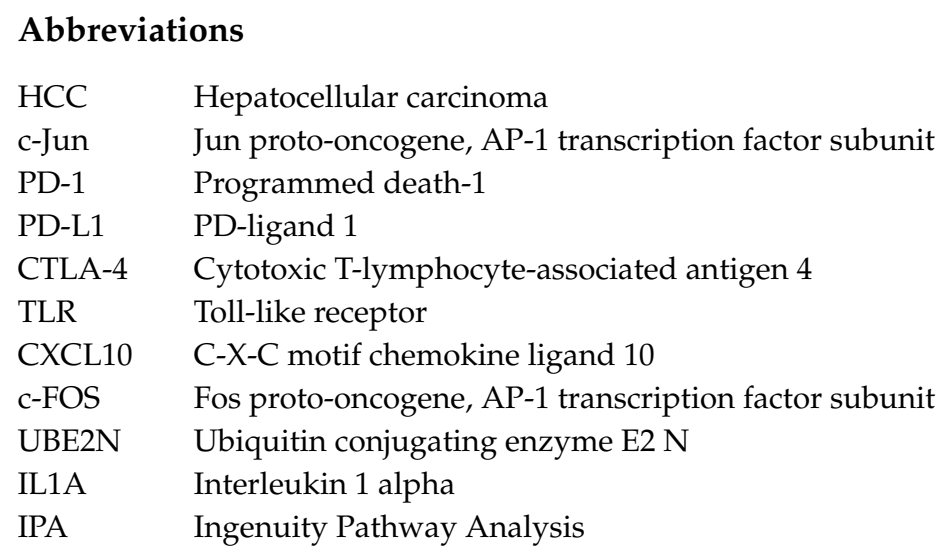

\section{References}

1. Global Burden of Disease Cancer Collaboration; Fitzmaurice, C.; Abate, D.; Abbasi, N.; Abbastabar, H.; Abd-Allah, F.; Abdel-Rahman, O.; Abdelalim, A.; Abdoli, A.; Abdollahpour, I.; et al. Global, Regional, and National Cancer Incidence, Mortality, Years of Life Lost, Years Lived with Disability, and Disability-Adjusted Life-Years for 29 Cancer Groups, 1990 to 2017: A Systematic Analysis for the Global Burden of Disease Study. JAMA Oncol. 2019, 5, 1749-1768. [CrossRef] [PubMed]

2. Okuda, K. Identification and localisation of resectable tumours in the liver. Trop. Gastroenterol. 1990, 11, 119-129. [PubMed]

3. Okuda, K. Hepatocellular carcinoma. J. Hepatol. 2000, 32, 225-237. [CrossRef]

4. Totoki, Y.; Tatsuno, K.; Covington, K.R.; Ueda, H.; Creighton, C.J.; Kato, M.; Tsuji, S.; Donehower, L.A.; Slagle, B.L.; Nakamura, H.; et al. Trans-ancestry mutational landscape of hepatocellular carcinoma genomes. Nat. Genet. 2014, 46, 1267-1273. [CrossRef] [PubMed]

5. Kanda, T.; Goto, T.; Hirotsu, Y.; Moriyama, M.; Omata, M. Molecular Mechanisms Driving Progression of Liver Cirrhosis towards Hepatocellular Carcinoma in Chronic Hepatitis B and C Infections: A Review. Int. J. Mol. Sci. 2019, 20, 1358. [CrossRef] [PubMed]

6. Llovet, J.M.; Bruix, J. Molecular targeted therapies in hepatocellular carcinoma. Hepatology 2008, 48, 1312-1327. [CrossRef]

7. Llovet, J.M.; Ricci, S.; Mazzaferro, V.; Hilgard, P.; Gane, E.; Blanc, J.F.; de Oliveira, A.C.; Santoro, A.; Raoul, J.L.; Forner, A.; et al. SHARP Investigators Study Group. Sorafenib in advanced hepatocellular carcinoma. N. Engl. J. Med. 2008, 359, 378-390. [CrossRef]

8. Cheng, A.L.; Kang, Y.K.; Chen, Z.; Tsao, C.J.; Qin, S.; Kim, J.S.; Luo, R.; Feng, J.; Ye, S.; Yang, T.S.; et al. Efficacy and safety of sorafenib in patients in the Asia-Pacific region with advanced hepatocellular carcinoma: A phase III randomised, double-blind, placebo-controlled trial. Lancet Oncol. 2009, 10, 25-34. [CrossRef]

9. Haga, Y.; Kanda, T.; Nakamura, M.; Nakamoto, S.; Sasaki, R.; Takahashi, K.; Wu, S.; Yokosuka, O. Overexpression of c-Jun contributes to sorafenib resistance in human hepatoma cell lines. PLoS ONE 2017, 12, e0174153. [CrossRef]

10. Hagiwara, S.; Kudo, M.; Nagai, T.; Inoue, T.; Ueshima, K.; Nishida, N.; Watanabe, T.; Sakurai, T. Activation of JNK and high expression level of CD133 predict a poor response to sorafenib in hepatocellular carcinoma. Br. J. Cancer 2012, 106, 1997-2003. [CrossRef]

11. Pinyol, R.; Montal, R.; Bassaganyas, L.; Sia, D.; Takayama, T.; Chau, G.Y.; Mazzaferro, V.; Roayaie, S.; Lee, H.C.; Kokudo, N.; et al. Molecular predictors of prevention of recurrence in HCC with sorafenib as adjuvant treatment and prognostic factors in the phase 3 STORM trial. Gut 2019, 68, 1065-1075. [CrossRef] [PubMed] 
12. Bruix, J.; Qin, S.; Merle, P.; Granito, A.; Huang, Y.H.; Bodoky, G.; Pracht, M.; Yokosuka, O.; Rosmorduc, O.; Breder, V.; et al. Regorafenib for patients with hepatocellular carcinoma who progressed on sorafenib treatment (RESORCE): A randomised, double-blind, placebo-controlled, phase 3 trial. Lancet 2017, 389, 56-66. [CrossRef]

13. Kudo, M.; Finn, R.S.; Qin, S.; Han, K.H.; Ikeda, K.; Piscaglia, F.; Baron, A.; Park, J.W.; Han, G.; Jassem, J.; et al. Lenvatinib versus sorafenib in first-line treatment of patients with unresectable hepatocellular carcinoma: A randomised phase 3 non-inferiority trial. Lancet 2018, 391, 1163-1173. [CrossRef]

14. Kudo, M. Systemic Therapy for Hepatocellular Carcinoma: Latest Advances. Cancers 2018, 10, 412. [CrossRef] [PubMed]

15. Yau, T.; Hsu, C.; Kim, T.Y.; Choo, S.P.; Kang, Y.K.; Hou, M.M.; Numata, K.; Yeo, W.; Chopra, A.; Ikeda, M.; et al. Nivolumab in advanced hepatocellular carcinoma: Sorafenib-experienced Asian cohort analysis. J. Hepatol. 2019, 71, 543-552. [CrossRef]

16. Finn, R.S.; Ryoo, B.Y.; Merle, P.; Kudo, M.; Bouattour, M.; Lim, H.Y.; Breder, V.; Edeline, J.; Chao, Y.; Ogasawara, S.; et al. Pembrolizumab as Second-Line Therapy in Patients with Advanced Hepatocellular Carcinoma in KEYNOTE-240: A Randomized, Double-Blind, Phase III Trial. J. Clin. Oncol. 2020, 38, 193-202. [CrossRef]

17. Ando, Y.; Yamauchi, M.; Suehiro, Y.; Yamaoka, K.; Kosaka, Y.; Fuji, Y.; Uchikawa, S.; Kodama, K.; Morio, K.; Fujino, H.; et al. Complete response to pembrolizumab in advanced hepatocellular carcinoma with microsatellite instability. Clin. J. Gastroenterol. 2020. [CrossRef]

18. Sangro, B.; Gomez-Martin, C.; de la Mata, M.; Iñarrairaegui, M.; Garralda, E.; Barrera, P.; Riezu-Boj, J.I.; Larrea, E.; Alfaro, C.; Sarobe, P.; et al. A clinical trial of CTLA-4 blockade with tremelimumab in patients with hepatocellular carcinoma and chronic hepatitis C. J. Hepatol. 2013, 59, 81-88. [CrossRef]

19. Seya, T.; Takeda, Y.; Takashima, K.; Yoshida, S.; Azuma, M.; Matsumoto, M. Adjuvant immunotherapy for cancer: Both dendritic cell-priming and check-point inhibitor blockade are required for immunotherapy. Proc. JPN. Acad. Ser. B. Phys. Biol. Sci. 2018, 94, 153-160. [CrossRef]

20. Zou, H.; Wang, W.K.; Liu, Y.L.; Braddock, M.; Zheng, M.H.; Huang, D.S. Toll-like receptors in hepatocellular carcinoma: Potential novel targets for pharmacological intervention. Expert. Opin. Ther. Targets 2016, 20, 1127-1135. [CrossRef]

21. Taguchi, D.; Inoue, M.; Fukuda, K.; Yoshida, T.; Shimazu, K.; Fujita, K.; Okuyama, H.; Matsuhashi, N.; Tsuji, A.; Yoshida, K.; et al. Therapeutic drug monitoring of regorafenib and its metabolite M5 can predict treatment efficacy and the occurrence of skin toxicities. Int. J. Clin. Oncol. 2019, 25, 531-540. [CrossRef] [PubMed]

22. Nagahama, M.; Ozeki, T.; Suzuki, A.; Sugino, K.; Niioka, T.; Ito, K.; Miura, M. Association of lenvatinib trough plasma concentrations with lenvatinib-induced toxicities in Japanese patients with thyroid cancer. Med. Oncol. 2019, 36, 39. [CrossRef] [PubMed]

23. Urban-Wojciuk, Z.; Khan, M.M.; Oyler, B.L.; Fahraeus, R.; Marek-Trzonkowska, N.; Nita-Lazar, A.; Hupp, T.R.; Goodlett, D.R. The Role of TLRs in Anti-Cancer Immunity and Tumor Rejection. Front. Immunol. 2019, 10, 2388. [CrossRef] [PubMed]

24. Krämer, A.; Green, J.; Pollard, J., Jr.; Tugendreich, S. Causal analysis approaches in Ingenuity Pathway Analysis. Bioinformatics 2014, 30, 523-530. [CrossRef] [PubMed]

25. Ren, T.; Zhu, L.; Cheng, M. CXCL10 accelerates EMT and metastasis by MMP-2 in hepatocellular carcinoma. Am. J. Transl. Res. 2017, 9, 2824-2837. [PubMed]

26. Wu, X.; Zhang, W.; Font-Burgada, J.; Palmer, T.; Hamil, A.S.; Biswas, S.K.; Poidinger, M.; Borcherding, N.; Xie, Q.; Ellies, L.G.; et al. Ubiquitin-conjugating enzyme Ubc13 controls breast cancer metastasis through a TAK1-p38 MAP kinase cascade. Proc. Natl. Acad. Sci. USA 2014, 111, 13870-13875. [CrossRef] [PubMed]

27. Malik, A.; Sharma, D.; Zhu, Q.; Karki, R.; Guy, C.S.; Vogel, P.; Kanneganti, T.D. IL-33 regulates the IgA-microbiota axis to restrain IL-1 $\alpha$-dependent colitis and tumorigenesis. J. Clin. Investig. 2016, 126, 4469-4481. [CrossRef]

28. León, X.; Bothe, C.; García, J.; Parreño, M.; Alcolea, S.; Quer, M.; Vila, L.; Camacho, M. Expression of IL-1 $\alpha$ correlates with distant metastasis in patients with head and neck squamous cell carcinoma. Oncotarget 2015, 6, 37398-37409.

29. Tomimatsu, S.; Ichikura, T.; Mochizuki, H. Significant correlation between expression of interleukin-1alpha and liver metastasis in gastric carcinoma. Cancer 2001, 91, 1272-1276. [CrossRef] 
30. Tamura, R.; Kanda, T.; Imazeki, F.; Wu, S.; Nakamoto, S.; Tanaka, T.; Arai, M.; Fujiwara, K.; Saito, K.; Roger, T.; et al. Hepatitis C Virus nonstructural 5A protein inhibits lipopolysaccharide-mediated apoptosis of hepatocytes by decreasing expression of Toll-like receptor 4. J. Infect. Dis. 2011, 204, 793-801. [CrossRef]

31. Wang, H.; Li, X.; Li, T.; Wang, L.; Wu, X.; Liu, J.; Xu, Y.; Wei, W. Multiple roles of microRNA-146a in immune responses and hepatocellular carcinoma. Oncol. Lett. 2019, 18, 5033-5042. [CrossRef] [PubMed]

32. Kudo, M. Combination Cancer Immunotherapy in Hepatocellular Carcinoma. Liver Cancer 2018, 7, $20-27$. [CrossRef] [PubMed]

33. Kato, Y.; Tabata, K.; Kimura, T.; Yachie-Kinoshita, A.; Ozawa, Y.; Yamada, K.; Ito, J.; Tachino, S.; Hori, Y.; Matsuki, M.; et al. Lenvatinib plus anti-PD-1 antibody combination treatment activates CD8+ T cells through reduction of tumor-associated macrophage and activation of the interferon pathway. PLOS ONE 2019, 14, e0212513. [CrossRef] [PubMed]

34. Di Domenicantonio, A. Rheumatoid arthritis and the alpha-chemokine IP-10. Clin. Ter. 2014, 165, e447-e451.

35. Kanni, T.; Argyropoulou, M.; Spyridopoulos, T.; Pistiki, A.; Stecher, M.; Dinarello, C.A.; Simard, J.; Giamarellos-Bourboulis, E.J. MABp1 Targeting IL- $1 \alpha$ for Moderate to Severe Hidradenitis Suppurativa Not Eligible for Adalimumab: A Randomized Study. J. Investig. Dermatol. 2018, 138, 795-801. [CrossRef]

36. Kuo, W.T.; Lee, T.C.; Yu, L.C. Eritoran Suppresses Colon Cancer by Altering a Functional Balance in Toll-like Receptors That Bind Lipopolysaccharide. Cancer Res. 2016, 76, 4684-4695. [CrossRef]

37. Kashani, B.; Zandi, Z.; Karimzadeh, M.R.; Bashash, D.; Nasrollahzadeh, A.; Ghaffari, S.H. Blockade of TLR4 using TAK-242 (resatorvid) enhances anti-cancer effects of chemotherapeutic agents: A novel synergistic approach for breast and ovarian cancers. Immunol. Res. 2020, 67, 505-516. [CrossRef]

38. Glaxo, S.K. A Phase I, 2-part (Part 1 Being a Single Dose Escalation and Part 2, a Parallel Group) Study of Toll-like Receptor (TLR4) Agonist (GSK1795091) in Healthy Subjects. Available online: https://clinicaltrials. gov/ct2/show/NCT02798978 (accessed on 10 February 2020).

39. Yesudhas, D.; Gosu, V.; Anwar, M.A.; Choi, S. Multiple roles of toll-like receptor 4 in colorectal cancer. Front. Immunol. 2014, 5, 334. [CrossRef]

40. Sasaki, R.; Kanda, T.; Nakamura, M.; Nakamoto, S.; Haga, Y.; Wu, S.; Shirasawa, H.; Yokosuka, O. Possible involvement of hepatitis B virus infection of hepatocytes in the attenuation of apoptosis in hepatic stellate cells. PLOS ONE 2016, 11, e0146314. [CrossRef]

41. Kanda, T.; Tada, M.; Imazeki, F.; Yokosuka, O.; Nagao, K.; Saisho, H. 5-aza-2'-deoxycytidine sensitizes hepatoma and pancreatic cancer cell lines. Oncol. Rep. 2005, 14, 975-979. [CrossRef]

42. Kanda, T.; Jiang, X.; Nakamoto, S.; Nakamura, M.; Miyamura, T.; Wu, S.; Yokosuka, O. Different effects of three interferons L on Toll-like receptor-related gene expression in HepG2 cells. Cytokine 2013, 64, 577-583. [CrossRef] [PubMed]

43. Kanda, T.; Steele, R.; Ray, R.; Ray, R.B. Hepatitis C virus infection induces the beta interferon signaling pathway in immortalized human hepatocytes. J. Virol. 2007, 81, 12375-12381. [CrossRef]

44. Ishida, Y.; Agata, Y.; Shibahara, K.; Honjo, T. Induced expression of PD-1, a novel member of the immunoglobulin gene superfamily, upon programmed cell death. EMBO J. 1992, 11, 3887-3895. [CrossRef]

45. Zhang, Q.; Zhang, H.; Ding, J.; Liu, H.; Li, H.; Li, H.; Lu, M.; Miao, Y.; Li, L.; Zheng, J. Combination Therapy with EpCAM-CAR-NK-92 Cells and Regorafenib against Human Colorectal Cancer Models. J. Immunol. Res. 2018, 2018, 4263520. [CrossRef] [PubMed]

46. Ghousein, A.; Mosca, N.; Cartier, F.; Charpentier, J.; Dupuy, J.W.; Raymond, A.A.; Bioulac-Sage, P.; Grosset, C.F. miR-4510 blocks hepatocellular carcinoma development through RAF1 targeting and RAS/RAF/MEK/ERK signalling inactivation. Liver Int. 2020, 40, 240-251. [CrossRef] [PubMed]

(C) 2020 by the authors. Licensee MDPI, Basel, Switzerland. This article is an open access article distributed under the terms and conditions of the Creative Commons Attribution (CC BY) license (http://creativecommons.org/licenses/by/4.0/). 